\title{
GROSS MORPHOLOGY OF THE BRAIN AND SPINAL CORD OF THE AFRICAN PYGMY HEDGEHOG (ATELERIX ALBIVENTRIS)
}

\author{
Igado, O. O., Braimah, S. F., Obasa, A. A. \\ Department of Veterinary Anatomy, Faculty of Veterinary Medicine \\ University of Ibadan, Oyo State \\ Nigeria
}

oo.igado@maill.ui.edu.ng; mayowaigado@yahoo.com

\section{ABSTRACT}

The African pygmy hedgehog (Atelerix albiventris) is an insectivorous animal, native to Africa. The central nervous system (CNS) consists of the brain and the spinal cord, protected by the cranium and vertebral column respectively. Assessment of the gross appearance and morphometries of the African pygmy hedgehog CNS were carried out using six adults ( 3 males and 3 females). The gross examination showed the brains to be lissencephalic, with relatively large olfactory bulbs, similar to that observed in some rodents. The rootlets of the first cervical spinal nerves were observed to emerge before the foramen magnum. Linear measurements were obtained from both the brain and spinal cord. The mean weight of the animals was $199.00 \pm 16.09 \mathrm{~g}$, with the males having an average body weight of $183.50 \pm 12.02 \mathrm{~g}$ and the females $206.80 \pm 11.95 \mathrm{~g}$. Although not statistically significant, the males had a higher encephalisation quotient $(0.40 \pm 0.08)$ relative to the females $0.36 \pm 0.04)$. The values for the brain weight, length of spinal cord and heights of the telencephalon and diencephalon at dif- ferent points were higher in the males, while the spinal cord weight, length of brain and cerebellar height were higher in the females. The spinal cord showed slight enlargements at the cervical, thoracic, lumbar and sacral segments. This study aimed to provide baseline data for the study of the gross appearance and neuromorphometrics of the hedgehog, with possible application in regional anaesthesiology and comparative wildlife neuroanatomy.

Key words: Atelerix albiventris; brain; morphometrics; spinal cord

\section{INTRODUCTION}

The central nervous system (CNS) consists of the brain and spinal cord. The brain is encased in the skull, while the spinal cord is continuous caudally with the brain and is protected by the vertebral column [21].

Atelerix albiventris (also known as the four-toed hedgehog) is the smallest of the African hedgehogs, belonging 
to the family Erinaceidae, subfamily Erinaceinae. It is one of the four species of the genus Atelerix. These hedgehogs are phenotypically small, short tailed and spiny, possessing a pointed muzzle. They have a well-developed sense of smell, sight and hearing [19]. They are terrestrial and placental mammals, nocturnally active and classified as "least concern" on the International Union for Conservation of Nature (IUCN). Their occurrence is widespread in Africa, they can be found in human habitation and are sexually dimorphic $[6,10]$. The hedgehogs are an important group of insectivores, they have relatively small brains with little neocortex, and for some decades have been employed to better understand the initial stages of the brain evolution of mammals [4]. In more recent years, African hedgehogs are becoming increasing popular as pets, with a lifespan of $1-4$ years in the wild [11]. In spite of the increasing importance of the hedgehog (as pets and experimental models), there are few studies detailing its anatomy in the absence of disease. These animals are kept as pets in many climes, resulting in them being in close contact with humans. This, among other reasons makes it imperative to study and understand the anatomy of this unique spine-bearing animal.

This study, the first in a series on the anatomy of the hedgehog CNS, aimed to assess the gross morphology and morphometrics of the brain and spinal cord of the African pygmy hedgehog. It is hoped that this study will lead to a better understanding of the hedgehog CNS, its similarity to other mammalian insectivores, provide the basis for future research as well as contribute to the knowledge of African pygmy hedgehog neuroanatomy.

\section{MATERIALS AND METHODS}

A total of six clinically healthy African pygmy hedgehogs ( 3 females and 3 males) were obtained from the forests around Ibadan, Oyo State, Nigeria. The animals were examined and determined to be free of any abnormality or deformity that could interfere with this study.

Each animal was weighed with a digital kitchen weighing scale (Electronic Kitchen Scale, Camry ${ }^{\circledR}$ EK5350, error of $1 \mathrm{~g}$, China) and sedated using an overdose of ketamine $\mathrm{HCl}$ injection, (150 mg. $\left.\mathrm{kg}^{-1}\right)$ and xylazine $\left(6 \mathrm{mg} \cdot \mathrm{kg}^{-1}\right)$ intramuscularly, adapted from $\mathrm{C}$ a $\mathrm{t}$ a $\mathrm{n}$ i a et al. [4]. Intracardiac perfusion commenced after cessation of respiration and lack of response to vigorous tactile stimuli. Intracardiac prefusion was performed using $0.9 \%$ normal saline followed by $4 \%$ paraformaldehyde (PFA), each solution about $300 \mathrm{ml}$. The cauda equinae could not be dissected out because it was very tiny, too fragile and delicate and was easily damaged.

Linear measurements and total weight were obtained on the brains and spinal cords before severing the brains immediately caudal to the obex. Individual weights and relative weights of the brain and spinal cord (relative to body mass) were also determined per animal.

A total of 16 gross linear parameters were measured on the brain and spinal cord. All linear measurements were determined with the aid of either a digital vernier calliper (Neiko ${ }^{\oplus}$, sensitivity of $0.01 \mathrm{~mm}$ ) or a centimetre rule, and were recorded in millimetres. Weights of the brain and spinal cord were obtained using an electronic digital pocket scale (Camry ${ }^{\circledR}$ Model EHA901, error of $0.01 \mathrm{~g}$ ) recorded in grams.

The parameters measured and their landmarks are defined below in Figures 1 and 2:

- Length of brain (LOB): Distance from the most rostral part of the olfactory bulb to the most caudal aspect of the cerebellum.

- Length of brain and spinal cord (LOBSC): Distance from the most rostral part of the brain to the most caudal part of the spinal cord measured in situ.

- Length of cerebrum (LOC): Distance from the most rostral point of the olfactory bulb to the most caudal aspect of the cerebrum, at the transverse fissure where it articulates with the cerebellum.

- Length of cerebellum (LOCB): Distance from the most rostral end of the cerebellum where the cerebellum makes contact with the cerebrum, to the most caudal point or far extremity rostral to the medulla oblongata.

- Width of cerebrum (WIOC): Maximum distance between the lateral aspects of the two cerebral hemispheres.

- Width of cerebellum (WIOCB): Maximum distance between the most lateral aspects of the cerebellum.

- Height of cerebrum (HOC): Distance from the ventral aspect of the brainstem to the most dorsal aspect of the cerebrum.

- Height of cerebellum (HOCB): Measured from the highest point of the median vermis to the roof of the fourth ventricle.

- Height of olfactory bulb (HOOB): This was measured 


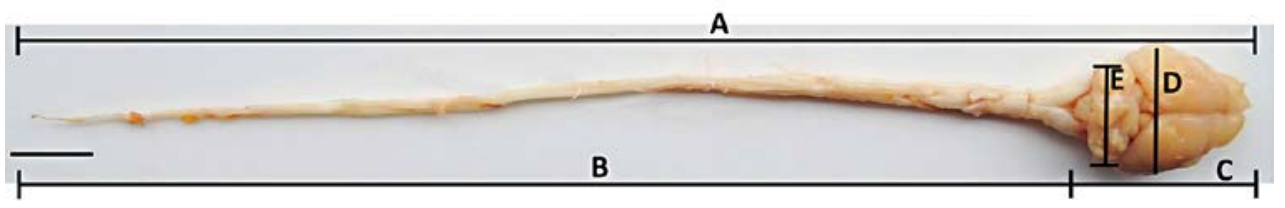

Fig. 1. Dorsal view of the brain and spinal cord of the African pygmy hedgehog, showing the length of the brain and spinal cord (A), the length of the spinal cord (B), the length of the brain (C), width of the cerebrum (D) and width of the cerebellum (E). Scale bar-1 $\mathrm{cm}$

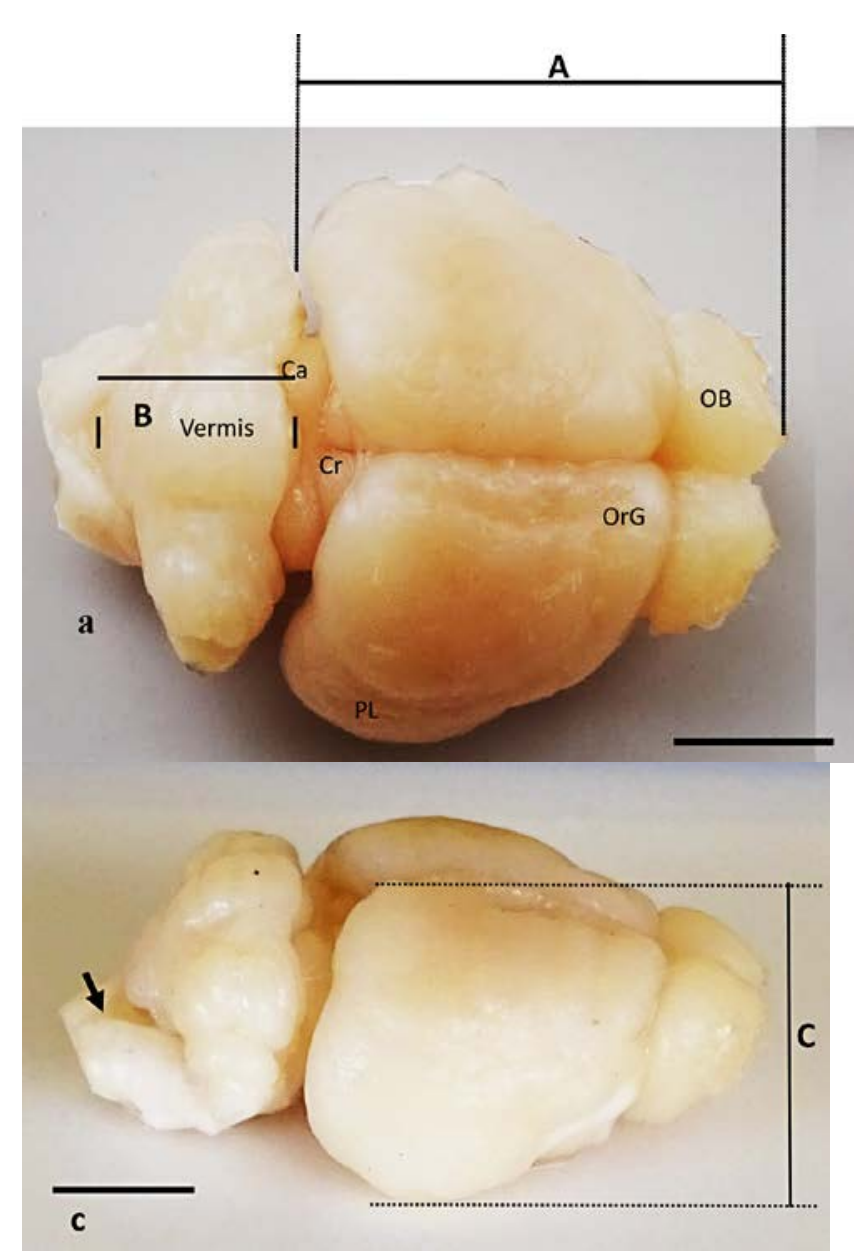

from the dorsal aspect of the olfactory bulb to the ventral aspect.

- Height of brain at the level of pons (HOBP): Distance from the dorsal aspect of the brain to the ventral aspect of the pons, at the root of the trigeminal nerve (cranial nerve V).

- Length of spinal cord (LOSC): Measurement of the spinal cord from its rostral limit, at the emergence of the first spinal nerve, to the tip of the conus medullaris.

- Diameter of the cervical enlargement of the spinal cord (CESC): Measurement of the thickness/width of the cranial expanded portion of the spinal cord.

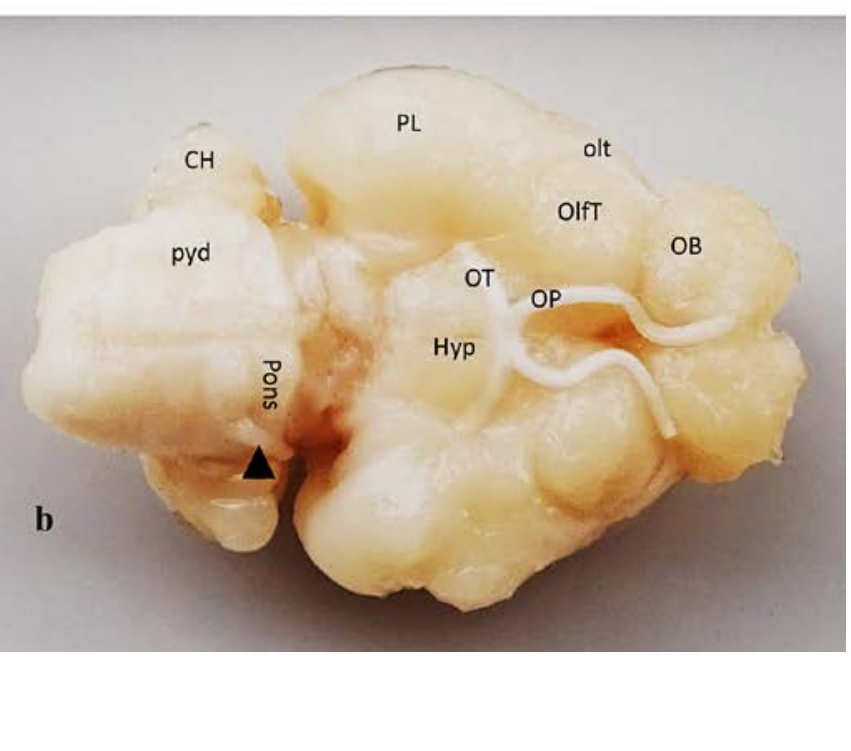

Fig. 2. Dorsal view (a), ventral view (b), and dorso-lateral view (c) of the hedgehog brain

$\mathrm{Ca}$-caudal colliculi; $\mathrm{Cr}$-cranial colliculi; OB_olfactory bulb; OrGorbital gyri; OlfT-olfactory tubercle; OP-optic nerve; OT-optic tract; $\mathrm{PL}$ - pyriform lobe; Hyp-hypothalamus; $\mathrm{CH}$-cerebellar hemisphere; olt-olfactory tract; pyd-pyramid; arrow head-CN VII; arrow (in c)-obex; A-length of cerebrum; B-length of cerebellum; $\mathrm{C}$-height of cerebrum. Scale bar $-0.5 \mathrm{~cm}$

- Diameter of the thoracic enlargement of the spinal cord (TESC): Thickness/width of the spinal cord, at the thoracic enlargement.

- Diameter of the lumbar enlargement of the spinal cord (LESC): Thickness/width of the spinal cord, at the lumbar region.

- Diameter of the sacral enlargement of the spinal cord (SESC): Thickness/width of the spinal cord, at the sacral region.

- Number of vertebrae (NOV): The total number of cervical, thoracic, lumbar, sacral and coccygeal vertebrae that form the vertebral column. 
The external features of the brain were photographed and visually examined from the dorsal, ventral and dorso-lateral views (Figs. 1 and 2). Naming of structures was adapted from texts and previous reports [12, 20, 21]. Encephalization quotient (EQ) was calculated based on the formula described by $\mathrm{C}$ a i r ó [3].

\section{Statistical analysis}

All data obtained were analysed with ANOVA, with Bonferroni post-test (Graphpad prism version 5, La Jolla, USA), and the level of significance was calculated at $\mathrm{P}<0.05$.

\section{Ethical statement}

All experimental protocols conformed to the ethics and guidelines for the care and use of experimental animals by the University of Ibadan, Ibadan, Oyo state, Nigeria and the National Institute of Health (NIH), USA. Ethical approval was obtained from the Animal Care Use and Research Ethics Committee (ACUREC) of the University of Ibadan, Nigeria, code UI-ACUREC/17/0023. Every effort was made to reduce suffering and bring any pain from handling to the barest minimum.

\section{RESULTS}

\section{General appearance of the CNS}

The most rostral structures of the telencephalon were the two distinct olfactory bulbs, which appeared relatively large compared to other mammalian species. Immediately caudal to the bulbs were the two separate cerebral hemispheres. The cerebrum was mostly lissencephalic (lacking gyri) in appearance, but the demarcation of the orbital gyri and the pyriform lobes were distinct. The corpora quadrigemina was observable from the dorsal aspect, with the caudal colliculi being bigger and more laterally extended. The ventral surface showed a clearly demarcated olfactory bulb, well-defined olfactory tubercle and tract, with the olfactory tract being more laterally placed. Caudal to the cerebrum was the cerebellum (comprising the median vermis and the two lateral hemispheres). Beneath these structures was the brain stem, which continued caudally as the spinal cord. The spinal cord possessed a cervical enlargement, and subsequently enlargements at the different segments (thoracic, lumbar and sacral). The mean EQ was $0.37 \pm 0.05$, with the males being $0.40 \pm 0.08$, while the females had a non-significant lower value of $0.36 \pm 0.04$. Of note was the fact that the first cervical spinal nerves were noted to emerge midway around the region of the occipital condyles.

\section{Morphometrics}

The results for linear measurements are presented in Table 1 as means \pm Standard Deviation (SD).

The mean weight of the African pygmy hedgehog used was $199.00 \pm 16.09 \mathrm{~g}$, males $183.50 \pm 12.02 \mathrm{~g}$ and females $206.80 \pm 11.95 \mathrm{~g}$. No statistically significant difference was observed between male and female body weights $(\mathrm{P}>0.05)$.

Of all the parameters measured, the females were observed to record higher values in only nine parameters (weight of spinal cord, lengths of brain and of cerebellum, widths of cerebrum and cerebellum, height of cerebellum, diameters of the thoracic, lumbar and sacral enlargements of the spinal cord). The values obtained for the length of the cerebrum was similar in both genders (male 11.53 \pm 0.23 ; female $11.57 \pm 1.50)$. All other parameters showed higher values in the male, although no statistically significant difference $(P>0.05)$ was observed in all parameters measured (Table 1).

The number of vertebrae was consistent in all animals assessed. The total number of vertebrae was 33 , with the vertebral formula C7T13L6S4Cd3.

The spinal segment length yielded varying results along the different regions of the spinal cord. The thoracic spinal segment had the most contribution to the spinal cord length as well as the number of spinal nerves while the sacral spinal segments contributed the least.

\section{DISCUSSION}

The knowledge of the gross anatomy of the nervous system is an essential tool in treating neurologic diseases, conditions of the CNS and in some medical manoeuvres like inducing local anaesthesia. Morphometric evaluations of the CNS and its surrounding tissues have proven useful in medical imaging, as in histopathological studies [5].

Although males are usually heavier than females of the same age and species, it was not so in this study probably due to the fact that the specific age of the animals examined were not known, since the hedgehogs were 
Table 1. Morphometric values of the brain and spinal cord of the African pygmy hedgehog, data presented as means \pm SD

\begin{tabular}{|c|c|c|c|c|}
\hline & $\begin{array}{l}\text { PARAMETERS } \\
\text { (unit) }\end{array}$ & $\begin{array}{l}\text { TOTAL } \\
(\mathrm{n}=6)\end{array}$ & $\begin{array}{l}\text { MALE } \\
(\mathrm{n}=3)\end{array}$ & $\begin{array}{l}\text { FEMALE } \\
(\mathrm{n}=3)\end{array}$ \\
\hline 1 & $\begin{array}{l}\text { Weight of animal } \\
{[g]}\end{array}$ & $199.00 \pm 16.09$ & $183.50 \pm 12.02$ & $206.80 \pm 11.95$ \\
\hline 2 & $\begin{array}{l}\text { Weight of brain and spinal cord } \\
\text { [g] }\end{array}$ & $2.00 \pm 0.17$ & $1.99 \pm 0.21$ & $2.01 \pm 0.16$ \\
\hline 3 & $\begin{array}{l}\text { Weight of brain } \\
{[\mathrm{g}]}\end{array}$ & $1.50 \pm 0.16$ & $1.52 \pm 0.19$ & $1.49 \pm 0.16$ \\
\hline 4 & $\begin{array}{l}\text { Weight of spinal cord } \\
{[g]}\end{array}$ & $0.49 \pm 0.08$ & $0.44 \pm 0.10$ & $0.53 \pm 0.02^{*}$ \\
\hline 5 & Encephalization quotient & $0.37 \pm 0.05$ & $0.40 \pm 0.08$ & $0.36 \pm 0.04$ \\
\hline 6 & $\begin{array}{l}\text { Length of brain } \\
{[\mathrm{mm}]}\end{array}$ & $21.24 \pm 0.96$ & $20.74 \pm 0.57$ & $21.61 \pm 1.08^{*}$ \\
\hline 7 & $\begin{array}{l}\text { Length of brain and spinal cord } \\
{[\mathrm{cm}]}\end{array}$ & $13.98 \pm 0.85$ & $14.34 \pm 0.68$ & $13.71 \pm 0.95$ \\
\hline 8 & $\begin{array}{l}\text { Length of cerebrum } \\
{[\mathrm{mm}]}\end{array}$ & $11.55 \pm 1.07$ & $11.53 \pm 0.23$ & $11.57 \pm 1.50$ \\
\hline 9 & $\begin{array}{l}\text { Length of cerebellum } \\
{[\mathrm{mm}]}\end{array}$ & $6.25 \pm 0.59$ & $6.22 \pm 0.60$ & $6.28 \pm 0.67^{*}$ \\
\hline 10 & $\begin{array}{l}\text { Length of spinal cord } \\
{[\mathrm{mm}]}\end{array}$ & $11.84 \pm 0.85$ & $12.23 \pm 0.61$ & $11.55 \pm 0.0 .96$ \\
\hline 11 & $\begin{array}{l}\text { Width of cerebrum } \\
{[\mathrm{mm}]}\end{array}$ & $13.84 \pm 1.95$ & $12.04 \pm 1.28$ & $15.19 \pm 0.93^{*}$ \\
\hline 12 & $\begin{array}{l}\text { Width of cerebellum } \\
{[\mathrm{mm}]}\end{array}$ & $11.97 \pm 1.12$ & $11.06 \pm 0.58$ & $12.66 \pm 0.92^{*}$ \\
\hline 13 & $\begin{array}{l}\text { Height of cerebrum } \\
{[\mathrm{mm}]}\end{array}$ & $8.63 \pm 0.46$ & $8.79 \pm 0.72$ & $8.50 \pm 0.19$ \\
\hline 14 & $\begin{array}{l}\text { Height of cerebellum } \\
{[\mathrm{mm}]}\end{array}$ & $6.36 \pm 0.69$ & $6.36 \pm 0.79$ & $6.37 \pm 0.73^{*}$ \\
\hline 15 & $\begin{array}{l}\text { Height of olfactory bulb } \\
{[\mathrm{mm}]}\end{array}$ & $4.58 \pm 0.30$ & $4.45 \pm 0.24$ & $4.68 \pm 0.33$ \\
\hline 16 & $\begin{array}{l}\text { Height of brain at the pons } \\
{[\mathrm{mm}]}\end{array}$ & $7.89 \pm 0.41$ & $8.19 \pm 0.47$ & $7.67 \pm 0.21$ \\
\hline 17 & $\begin{array}{l}\text { Cervical enlargement diameter } \\
{[\mathrm{mm}]}\end{array}$ & $3.12 \pm 0.13$ & $3.10 \pm 0.22$ & $3.14 \pm 0.04$ \\
\hline 18 & $\begin{array}{l}\text { Thoracic enlargement diameter } \\
{[\mathrm{mm}]}\end{array}$ & $2.21 \pm 0.22$ & $2.05 \pm 0.26$ & $2.32 \pm 0.07^{*}$ \\
\hline 19 & $\begin{array}{l}\text { Lumbar enlargement diameter } \\
{[\mathrm{mm}]}\end{array}$ & $1.41 \pm 0.12$ & $1.35 \pm 0.16$ & $1.46 \pm 0.06^{*}$ \\
\hline 20 & $\begin{array}{l}\text { Sacral enlargement diameter } \\
{[\mathrm{mm}]}\end{array}$ & $0.74 \pm 0.09$ & $0.68 \pm 0.11$ & $0.79 \pm 0.05^{*}$ \\
\hline 21 & Number of vertebrae & $33.00 \pm 0.00$ & $33.00 \pm 0.00$ & $33.00 \pm 0.00$ \\
\hline
\end{tabular}

* -Indicates values which were higher in females relative to males No statistically significant difference was observed in all parameters measured $(P>0.05)$ 
captured from the wild, only the age range was known. This is however similar to other reports in goats [15]. The brain of the hedgehogs in this study accounted for about $0.85 \pm 0.24 \%$ of the total body weight which is considerably less than the $2 \%$ reported in humans $[2,18]$, while that of the spinal cord accounted for about $0.26 \%$ of the total body weight. The relative spinal cord weight of $0.26 \%$ is the same as the value reported for the African giant rat $(0.26 \%)$ and about half of what was reported in the rabbit [7].

Although slight and not statistically significant, the height, width and length of the cerebellum were higher in the females. This may probably indicate that the females likely possess finer motor dexterity and better cognitive ability, as cerebellar volume has been shown to have a positive correlation to general intelligence and fine motor dexterity; while also contributing to several aspects of cognition [17].

In spite of the fact that the males recorded higher values for the brain weight and height, the females recorded slightly higher values for the length of the brain. This difference may be attributed to the longer length of cerebellum in the females. The heavier brain weight recorded in the males is similar to what was obtained in pigs [14], although the male pigs recorded higher values for brain length while the females recorded higher values for brain height.

The encephalization quotient (EQ) is regarded as "a more complex and approximate alternative to measures of cognition. It takes into account the allometric effects of widely divergent body sizes" [3]. Values obtained are similar to those observed in the domestic pig, 0.39 [13], considerably smaller than that observed in the shrew, 2.54, and the dolphin, 5 [3]. In this study, the males showed a higher EQ value, although not statistically significantly different. Since more recent studies are taking EQ to calculate intelligence $[1,3,8,13]$, it will be interesting to assess which of the genders in this species will be shown to be more intelligent, noting that the values for the linear measurements of the cerebellum were higher in the females.

The African pygmy hedgehog spinal cord was observed to begin at the same level with the middle of the occipital condyles, where the most cranial rootlets of the first cervical spinal nerve roots emerge. However, previous reports state the cranial limit of the spinal cord to be at the foramen magnum in all domestic animals $[9,20]$.
Apart from the smaller number of the caudal bones, the vertebral formula was similar to that observed in the African giant rat [16].

\section{CONCLUSIONS}

This study provides basic topographic and macro-morphometric reference data on the African pygmy hedgehog brain and spinal segments that may be useful in applied research for regional anaesthesiology, diagnostic medical imaging in brain and spinal cord diseases, veterinary neuroanatomy and also comparative and regional anatomy. Data documented from this may provide a basis for future research as well as contribute to the knowledge of African pygmy hedgehog anatomy.

\section{CONFLICT OF INTEREST}

The authors declare there are no conflicts of interest.

\section{ACKNOWLEDGEMENT}

The authors gratefully acknowledge the technical assistance of Mr. A. W. Ramoni of the Department of Veterinary Anatomy, University of Ibadan, Nigeria.

\section{REFERENCES}

1. Aguirre, M. P., Fernandes, H. B. F., Woodley, M. A., 2017: Relative brain size, encephalization quotient. In Shackelford, T., Weekes-Shackelford, V., (Eds.): Encyclopedia of Evolutionary Psychological Science, Springer, New York, 1-3.

2. Bigos, K., Hariri, A., Weinberger, D., 2015: Neuroimaging Genetics: Principles and Practices. Oxford University Press, $432 \mathrm{pp}$.

3. Cairó, O., 2011: External measures of cognition. Front. Hum. Neurosci., 5, 108. DOI: 10.3389/fnhum.2011.00108.

4. Catania, K. C., Collins, C. E., Kaas, J. H., 2000: Organization of sensory cortex in the East African hedgehog (Atelerix albiventris). J. Comp. Neurol., 421, 2, 256-274. DOI: 10.1002/(SICI)1096-9861(20000529)421:2<256::AID-C NE10>3.0.CO;2-Y. 
5. Claridge, H. A., Piercy, R. J., Parry, A., Weller, R., 2010: The $3 \mathrm{D}$ anatomy of the cervical articular process joints in the horse and their topographical relationship to the spinal cord. Equine Vet. J., 42, 8, 726-731.

6. Deef, L. E. M., 2019: First record of Atelerix albiventris (family Erinaceidae) from South-Eastern of Egypt confirmed by molecular analysis. Pak. J. Zool., 51, 1, 9-14.

7. Farag, F., Elayat, M., Wally, Y., Eikarmoty, A., 2012: Morphometric studies on the spinal cord segments of the domestic rabbit (Oryctolagus cuniculus). J. Vet. Anat., 5, 2, 33-47. DOI: 10.21608/jva.2012.44873.

8. Fernandes, H. B. F., Peñaherrera-Aguirre, M., Woodley, M. A., 2020: Macroevolutionary patterns and selection modes for general intelligence $(G)$ and for commonly used neuroanatomical volume measures in primates. Intelligence, 80, 101456. DOI: 10.1016/j.intell.2020.101456.

9. Getty, R., 1975: The Anatomy of the Domestic Animals, Vol. 1 \& 2, 5th edn., Philadelphia, PA, Saunders Co., 2095 pp.

10. Girgiri, I. A., Gambo, B. G., Ibrahim, B., Bwala, A., 2015: Morphometric studies of some visceral organs and gastrointestinal tract of four-toed African hedgehog (Atelerix albiventris). J. Morphol. Sci,. 32, 1, 29-32. DOI: 10.4322/jms.071014.

11. Heatley, J. J., Mauldin, G. E., Cho, D. Y., 2005: A review of neoplasia in the captive African hedgehog (Atelerix albiventris). Semin. Avian Exot. Pet. Med., 14, 3, 182-192. DOI: 10. 1016/j.saep.2005.07.002.

12. Imam, A., Ajao, M. S., Bhagwandin, A., Ihunwo, A. O., Manger, P. R., 2017: The brain of the tree pangolin (Manis tricuspis). I. General appearance of the central nervous system. J. Comp. Neurol., 525, 11, 2571-2582. DOI: 10.1002/ cne.24222.
13. Minervini, S., Accogli, G., Pirone, A., Gra, J., Cozzi, B., Desantis, S., 2016: Brain mass and encephalization quotients in the domestic industrial pig (Sus scrofa), PLOS ONE, 11, 6, e0157378. DOI: 10.1371/journal.pone.0157378.

14. Olopade, J. O., Igado, O. O., Nwafor, C. I., Alamu, A. O., Onwuka, S. K., 2011: Some aspects of the craniofacial indices and macro neurometrics of the Nigerian local pig (Sus scrofa). Ital. J. Anat. Embryol., 116, 1, 38-44.

15. Olopade, J. O., Onwuka, S. K., 2004: Morphometric studies of the cranio-facial region of the West African dwarf goat in Nigeria. Int. J. Morphol., 22, 2, 145-148.

16. Olude, M. A., Mustapha, O. A., Ogunbunmi, T. K., Olopade, J. O., 2013: The vertebral column, ribs, and sternum of the African giant rat (Cricetomys gambianus Waterhouse). Sci. World J., 2013:973537. DOI: 10.1155/2013/973537.

17. Paradiso, S., Andreasen, N. C., O’Leary, D. S., Arndt, S., Robinson, R. G., 1997: Cerebellar size and cognition: Correlations with IQ, verbal memory and motor dexterity. Neuropsychiatry. Neuropsychol. Behav. Neurol., 10, 1, 1-8.

18. Parent, A., Carpenter, M. B., 1996: Carpenter's Human Neuroanatomy. 9th edn., Williams and Wilkins. $2171 \mathrm{pp}$.

19. Santana, E. M., Jantz, H. E., Best, T. L., 2010: Atelerix albiventris (Erinaceomorpha: Erinaceidae). Mamm. Species, 42, 857, 99-110. DOI: 10.1644/857.1.

20. Singh, B., 2017: Dyce, Sack and Wensing's Textbook of Veterinary Anatomy. 5th edn., Saunders, Elsevier, 872 pp.

21. Thomson, C. E., Hahn, C., 2012: Veterinary Neuroanatomy: A Clinical Approach. 1st edn., Saunders, Elsevier, 178 pp.

Received March 5, 2021

Accepted August 3, 2021 